ARTIGOS

\title{
O terapeuta e o contrato terapêutico: em busca de possibilidades $^{1}$
}

\section{The therapist and the therapeutic contract: in search of possibilities}

\section{Maurício S. Neubern*}

Professor adjunto do Instituto de Psicologia da Universidade de Brasília - UnB, Brasília, DF, Brasil

\begin{abstract}
RESUMO
O presente trabalho tem como objetivo demonstrar como é possível ao terapeuta proporcionar um legítimo contrato terapêutico com seu cliente, apesar dos obstáculos de ordem teórica e técnica. Ressalta que o contrato envolve regras de negociação de caráter objetivo, mas só se configura enquanto contrato terapêutico a partir da vinculação emocional de seus protagonistas. Partindo de três histórias clínicas de pacientes atendidas numa instituição, o trabalho enfatiza como atitudes por parte do terapeuta podem implicar na consideração com o outro e na criação de um contexto pragmático, que são fundamentais para o engajamento do cliente na proposta da psicoterapia. Em sua conclusão, destaca que o terapeuta, para assumir tais atitudes, possua flexibilidade diante de seu marco teórico, como ainda a compreensão de que, devido à singularidade das pessoas, o processo terapêutico pode acontecer de formas diversificadas.
\end{abstract}

Palavras-Chave: Contrato terapêutico, Vínculo, Psicoterapia, Atitudes.

\begin{abstract}
The present work has the objective to demonstrate how feasible it is for the therapist to provide his client with a legitimate therapeutic contract, despite the obstacles involving theory and practice. Also, it reinforces the fact that the contract deals with rules of negotiation under an objective character, but it only remains as a therapeutic contract as a result of a linkage between its protagonists. Analyzing three clinic cases of patients in a institution, such work highlights how fundamental are the actions on the part of therapists which implicate in the consideration with the other and the creation of pragmatic context are fundamental for the engagement of the client in the purpose of the psychotherapy. In its conclusion, the present work states that for the therapist to undertake such actions, it paramount that he have flexibility before his theoretic references, as well as understand that, due to people singularity, the therapeutic process may take place in diversified manners.
\end{abstract}

Keywords: Therapeutic contract, Linkage, Psychotherapy, Actions. 
A compreensão do contrato terapêutico como algo que vai além do estabelecimento de regras objetivas e remete a um engajamento emocional encontra-se discutida em diferentes abordagens seja em termos de psicoterapia, seja em termos de clínica de um modo geral (LÉVY, 1997). Nesse sentido, é possível destacar a ênfase conferida a questões de ordem técnica, como ainda a ênfase conferida a questões intersubjetivas como a aceitação do outro e a disposição para uma compreensão profunda de sua história de maneira a se promover um contexto propício ao processo terapêutico em si (ANDERSON, 1997; ANDERSON; GEHART, 2007; ERICKSON; ROSSI, 1979; WHITE, 2007; YAPKO, 2001). A figura do terapeuta, portanto, possui uma importância central para facilitar o engajamento do sujeito no processo terapêutico, tanto por poder transmitir-lhe segurança em função de técnicas que respondam a suas necessidades, como de proporcionar-lhe um espaço acolhedor e respeitoso onde suas demandas sejam devidamente consideradas. Assim sendo, é possível conceber que suas ações diante do cliente são de grande importância para que o contrato não se restrinja a um conjunto de regras de trabalho (como horários, pagamentos, férias, dentre outras) e se constitua num dos momentos fundamentais da relação terapêutica, caracterizando-se pelo engajamento de seus protagonistas quanto a uma proposta específica, seja de promover mudanças, aliviar sintomas ou proporcionar 0 crescimento emocional do cliente (WOLBERG, 1967).

No entanto, não é incomum que as ações do terapeuta não consigam promover a construção de um contrato legítimo em função de determinados obstáculos que podem remeter a diferentes dimensões (NEUBERN, 2004; 2005a). Em certas circunstâncias, o apego a conceitos teóricos e procedimentos técnicos o impedem de desenvolver uma compreensão pertinente sobre o cliente e, o que for trazido por ele, acaba sendo reduzido a alguma categoria teórica consagrada que pouco diz a respeito de sua experiência vivida. É assim que queixas ligadas ao desemprego, à competição no trabalho, à violência e a uma doença crônica podem ser facilmente reduzidas a categorias como padrões disfuncionais de relação, problemas mal resolvidos e longínquos da infância ou a um diagnóstico psiquiátrico (ANDERSON; GOOLISHIAN, 1993; GERGEN; KAYE, 1998). Esse tipo de enrijecimento do pensar do terapeuta, além de Ihe proporcionar uma pseudo-segurança diante do campo obscuro da clínica, também é útil para conquistar a simpatia de seus pares, tantas vezes preocupados em estabelecer diferenças entre o conhecimento psicológico e o saberes pouco confiáveis aos olhos da ciência (FIGUEIREDO, 1996; ROUSTANG, 1991). O problema é que tal apego aos referenciais teóricos e suas promessas de saber científico, 
freqüentemente, inviabiliza a efetivação do contrato e proporciona considerável distanciamento do cliente que pode se sentir desvalorizado e até desistir do processo terapêutico (ERICKSON; ROSSI, 1979; HALEY, 2001).

Outra fonte de obstáculos às ações do terapeuta, muito ligada ao que foi descrito acima, refere-se a processos institucionais que podem facilmente incluir interesses que acabam concorrendo com as demandas do cliente (GONZALEZ REY, 2007; VIEIRA FILHO; NÓBREGA, 2004; NEUBERN, 2005a). A rigidez de determinados procedimentos e regras, o apego a protocolos de pesquisa e levantamentos de informações, a fixação na seqüência de determinadas rotinas de serviço, a preocupação excessiva com aspectos financeiros e produção científica são alguns exemplos de ações que se impõem como prioritárias ao terapeuta que, caso não consiga se flexibilizar quanto às mesmas, corre sério risco de favorecer um processo sutil de desqualificação do cliente e suas queixas. Tais processos, que muitas vezes remetem a disputas políticas no seio da instituição, podem exigir uma fidelidade inconteste ao terapeuta que, ao cumpri-la, facilmente tem seu pensar adoecido, ficando estagnado, repetitivo e superficial $(\mathrm{KOCH}, 1981$; MORIN, 1991) de maneira a se restringir a um cumpridor mecânico de rotinas. Nesse sentido, se ele abandona sua condição de sujeito (MORIN, 1991; NEUBERN, 2005b), expressa por meio de seu potencial de reflexão e criação, não é difícil que o cliente passe a confirmar uma série de crenças negativas sobre a instituição e aumente em muito sua indisposição para aderir aos processos terapêuticos por ela oferecidos.

Diante do exposto, o presente trabalho tem como objetivo demonstrar, através de três histórias clínicas, como é possível ao terapeuta se posicionar diante de alguns obstáculos de maneira a proporcionar a construção de um legítimo contrato terapêutico com seu cliente. Tais histórias possuem um caráter ilustrativo e, não consistindo em estudos de caso detalhados, conferem maior ênfase aos obstáculos de ordem teórica e técnica em termos dos riscos de enrijecimento do pensar que podem facilmente inviabilizar o processo terapêutico. Nesse sentido será destacado de que modo atitudes como a consideração com o outro e a proposta de um contexto pragmático (ERICKSON, 1985; ERICKSON; ROSSI, 1979) são fundamentais para a efetivação do contrato terapêutico, principalmente por privilegiar 0 atendimento das necessidades dos clientes.

Vale ainda ressaltar que as histórias clínicas aqui descritas referem-se a atendimentos de três clientes mulheres que possuíam demandas ligadas a dores crônicas e recorreram a técnicas de hipnose e psicoterapia na clínica escola de uma universidade. As três clientes estavam sob 
acompanhamento médico devido a suas dores que já duravam vários meses. Os atendimentos, que ocorreram numa perspectiva de terapia breve (ERICKSON, 1985) cumprindo em torno de 6 a 8 sessões, foram conduzidos pelo pesquisador (o autor deste trabalho) e registrados por filmagens e anotações pelo grupo de pesquisa, no qual alguns integrantes observaram os casos pelo espelho unidirecional.

\section{Histórias Clínicas}

Dona Silvia, 57 anos, era uma estudante do grupo de estágio e sentia dores muito intensas nas costas e no joelho esquerdo, acometido de uma artrose. Movia-se com dificuldade e vez por outra era vista chorando discretamente em algum canto da clínica escola de maneira que, quando interrogada, respondia apenas que "tinha que se formar de qualquer jeito". Dona Silvia vivia um impasse considerável quanto a sua situação, pois, enquanto o médico lhe recomendava repouso absoluto, havia o forte desejo de se formar em psicologia e realizar um sonho e também de se casar novamente, mudando-se de cidade. Porém, Dona Silvia ocupava um lugar de cuidadora na sua família, tanto de questões emocionais e financeiras e era colocada, frequentemente, em outra situação contraditória, pois ao mesmo tempo em que seus familiares the exigiam obediência às ordens do médico, esperavam que ela continuasse a cuidar dos problemas emocionais e financeiros da família. Para agravar ainda mais sua situação, antes de morrer seu pai havia lhe dito que sua mãe não estaria mais presente na época de sua formatura e isso Ihe trazia uma intensa aflição, pois, para ela, consistia numa espécie de profecia e a formatura ocorreria em poucos meses. Tal quadro era marcado por momentos que pareciam assumir um caráter de oposição irreconciliável na subjetividade de Dona Silvia, envolvendo a relação entre si e os outros. Isto porque, investir em si de alguma forma, como a formatura, o casamento e o auto-cuidado, colocava-se como algo contrário à sua missão familiar de cuidar, ser uma boa cristã e à própria vida de sua mãe. Concluir a formatura poderia implicar na morte de alguém muito especial - sua mãe - o que, possivelmente, fizesse com que ela assumisse a culpa por algo tão terrível. Daí a sensação de paralisia, de uma impossibilidade vivida de mover-se e de uma dor de alma e de corpo que a fazia sofrer consideravelmente, sem que os tratamentos médicos e fisioterápicos pudessem lhe trazer algum alívio.

O pesquisador, então, Ihe propôs o atendimento clínico no próprio grupo do estágio, destacando que ambos tinham um problema, pois ela possuía uma doença de origem orgânica e o médico já lhe havia dito o que fazer. Disse ainda que não repetiria o que todos deveriam estar the 
dizendo e que confiaria nela quanto às providências que deveria tomar, enquanto, de sua parte, trabalharia com a hipnose. Após uma sessão em que a paciente sentiu considerável alívio de suas dores, o pesquisador ainda lhe propôs que ela poderia, de fato, escrever sua monografia, pois já havia pensado bastante nela e só faltava colocá-la, aos poucos, no papel. Então, ela faria o teste de, estando de repouso em sua cama, gravar suas falas sobre a monografia, pedir a alguém que as transcrevesse e, em seguida, revisar o texto numa posição confortável. Tal maneira de trabalhar a animou consideravelmente, uma vez que pôde dar continuidade a seus planos, escrever a monografia e, principalmente, atender as prescrições médicas de repouso. Após, esses momentos iniciais, Dona Silvia disse estar vislumbrando, depois de muito tempo e lágrimas, um futuro acessível e possível a suas pretensões.

Entretanto, durante os transes hipnóticos, Dona Silvia relatou estar vendo seu pai e estar sentindo toda a carga de peso em seu corpo que, provavelmente, estaria ligada à profecia da morte de sua mãe. O pesquisador procedeu retomando alguns momentos históricos afetivos e positivos entre ela e o pai, ao mesmo tempo em que a convidava a visualizar a aparência atual de seu pai, como seus cabelos, suas roupas, seus olhos e, sobretudo, seu semblante. Então, Dona Silvia se emocionou e disse que seu pai havia lhe beijado e vinha pedir perdão pelo que havia dito, pois apenas Deus teria o poder de prever a morte das pessoas. Para ela as visões de seu pai durante o transe não se tratavam de um processo de imaginação, mas de um legítimo encontro espiritual que traziam muita felicidade por ter notícias de seu pai e aliviar suas dores. Tendo cumprido as recomendações médicas e os exercícios fisioterápicos, ela pôde concluir seus planos, como o trabalho final, a formatura e o casamento e, embora tenha modificado aspectos importantes da relação com os familiares, continuou mantendo seu papel de cuidadora na família.

Em outra situação, Dona Marlene, 48 anos, divorciada, buscou terapia por intermédio de um de seus filhos que havia visto uma palestra do pesquisador. Sentia dores muito intensas pelo corpo, oriundas de uma fibromialgia que já durava mais de dois anos e encontrava-se num processo depressivo. Quando ouviu falar no trabalho de pesquisa, disse a seu filho: "se é uma pesquisa, então, o negócio é sério." Ao chegar, relatou que seus tratamentos anteriores não haviam levado a lugar algum; que os médicos do convênio eram como os do serviço público que nem lhe olhavam no rosto e prescreviam um medicamento; e que o último médico a enviou a um psiquiatra que também não a ouviu e prescreveu alguns antidepressivos. Revoltada com a falta de atenção, 
jogou todos os remédios no lixo e ficou sem saber onde buscar ajuda. Após duas sessões em que relatou se sentir aliviada de algumas dores, disse ao pesquisador que, se quisesse trabalhar com ela, deveria conhecê-la melhor, pois "não sabia da missa a metade". O pesquisador, ao invés de dar continuidade ao trabalho hipnótico programado, simplesmente colocou-se para escutá-la por quase duas horas nas quais Dona Marlene contou sua história, perpassada por muitos acontecimentos de intenso sofrimento, como as humilhações de seu marido, a perda do emprego, o suicídio do novo companheiro, seu isolamento atual e a eclosão de suas dores.

Ouvindo-a com atenção, o pesquisador disse que tinha sido muito bom para ele conhecer mais da metade da missa, mas que ele também teria outras "coisas dessa missa para lhe contar na próxima sessão". Nesta, em situação de transe hipnótico, contou-Ihe a metáfora sobre a instabilidade do clima de Brasília, onde as pessoas podem viver o Sol e a chuva, o frio e o calor num mesmo dia e ainda podem aproveitar isso; que a vida das pessoas pode possuir muito sofrimento e que elas podem crescer com isso; e que ela, Marlene, havia conseguido vir para uma cidade grande, tirar a carteira sem ajuda, fazer bons amigos, conseguir seu trabalho, ser respeitada em sua profissão e criar três filhos responsáveis e estudiosos. Por meio dessas técnicas, os aspectos positivos passaram a ganhar maior visibilidade em suas narrativas, auxiliando Dona Marlene a deixar a depressão, retomar sua vida social e aliviar consideravelmente suas dores.

Já o caso de Dona Paula, 49 anos, estava ligado a um grande sofrimento devido à perda de sua irmã mais próxima e querida. Além das dores intensas de fibromialgia, há aproximadamente seis meses ela não trabalhava, mal dormia e se alimentava, como ainda havia se afastado da maioria de seus espaços de convívio social. Era comum que chorasse escondido dos outros, em algum lugar afastado da casa ou de madrugada, o que costumava ser reprovado pelos familiares que diziam não suportar mais vê-la assim. Mas o que chamou a atenção do pesquisador desde o início foram os sentidos contraditórios envolvendo seu ato de chorar. Isto porque era talvez a única forma de expressão de um sofrimento intenso que possuía, mas, ao mesmo tempo, uma forma que para si e sua família era um sinal de fraqueza (pois "choro é coisa de gente fraca") e um sinal de perturbação espiritual, já que seu choro atrapalharia a evolução da irmã no plano astral e impediria seu contato com a mesma durante os sonhos, segundo as crenças da religião de sua família. Envolvida em semelhante conflito, Dona Paula tinha a sensação de completa paralisação de seu mundo, de um corpo pesado e sofrido, de uma profunda solidão e de um bloqueio tão grande que a impedia de 
vislumbrar qualquer traço do futuro. Entretanto, ela estava ali encaminhada por uma profissional de saúde com quem possuía um bom vínculo e dizia estar disposta a colaborar com o trabalho que o "doutor" (no caso, o pesquisador) Ihe oferecia.

O pesquisador, diante deste quadro, após uma escuta atenta de sua queixa, disse que poderia ajudá-la, mas seria necessário que ela fizesse algo muito difícil. Ele acreditava que ela conseguiria realizar tal tarefa, mas que isso não seria muito fácil, pois talvez mexesse muito com ela. Então, com seu compromisso de aceitar a tarefa, o pesquisador lhe propôs que colocasse uma foto de sua irmã entre os santos de seu altar e que chorasse ali o quanto quisesse e que caso alguém da família lhe perguntasse sobre isso, ela deveria dizer que fazia parte do novo tratamento e que poderiam buscar esclarecimento com o próprio pesquisador. Tal tarefa deveria ser realizada em alguns horários préestabelecidos pela paciente e também quando sentisse muita saudade de sua irmã. Após a realização desta tarefa, juntamente com outros procedimentos técnicos, Dona Paula sentiu uma melhora significativa de suas dores, retomou sua vida social e seu espaço de cuidadora na família e já estava se preparando para retornar ao trabalho. Além de voltar a dormir e comer bem, a paciente passou a se posicionar de outra forma diante do choro, prescrevendo-o como forma de terapia aos parentes que ainda sofriam com a perda da irmã. Na última sessão, relatou ter tomado café com sua irmã durante o transe hipnótico, tendo finalmente notícias de que ela estava bem.

\section{Promovendo o Contrato Terapêutico}

A despeito das várias possibilidades de compreensão sobre a promoção, por parte do terapeuta, de um contrato terapêutico legítimo e eficaz, os exemplos clínicos acima descritos podem destacar duas atitudes de grande importância. A princípio eles se referem, de forma ampla, a uma atitude de reconhecimento do outro, que considera o sujeito não como um conjunto de conceitos teóricos, mas como uma pessoa concreta e singular, em seus processos de produção de sentidos e em suas necessidades subjetivas. O que é importante para esta pessoa naquele momento, o que ela gostaria de receber do terapeuta, como ela enxerga e vivencia sua situação atual, como ela se sente em meio às realidades geradas a partir de sua situação são algumas das questões que não podem passar desapercebidas ao terapeuta. É importante que ele transmita atenção e interesse genuínos sobre essas questões de maneira a comunicar ao sujeito, de alguma forma, uma consideração legítima com sua pessoa. Uma vez que o cliente percebe uma disposição do terapeuta para aceitá-lo e compreendê-lo existem maiores 
possibilidades de que ele se disponha à terapia, que participe da construção de um contexto de mudança e crie confiança na pessoa do terapeuta, mesmo que não compreenda inteiramente o que ela faz. Semelhante atitude, além de criar a perspectiva de uma relação compartilhada, uma espécie de chão comum em termos afetivos (BINSWANGER, 1935), pode possibilitar uma relação distinta do sujeito consigo mesmo, onde este passa a acreditar mais em si e a mobilizar, com mais facilidade e maestria, seus próprios recursos (ERICKSON; ROSSI, 1979).

Por outro lado, outra atitude importante do terapeuta na promoção do contrato terapêutico refere-se à pontuação da terapia como um processo pragmático no sentido da criação de um contexto voltado para a construção de soluções que atendam às necessidades do sujeito. Ou seja, é importante que as soluções busquem contemplar os sentidos subjetivos, os significados, as emoções, as trocas sociais, o modo de expressão que são particulares a esta pessoa (e não de uma teoria a priori) e se organizam em torno de suas necessidades. Embora semelhante perspectiva seja ressaltada nas psicoterapias de um modo geral, não é raro que o terapeuta busque atender suas próprias necessidades teóricas e técnicas e desconsidere ou deixe para um segundo plano as necessidades e processos do sujeito (GONZALEZ REY, 2007; NEUBERN, 2004). O contexto pragmático, aqui ressaltado, referese à importância de uma compreensão da singularidade desse sujeito, em termos de suas características, recursos e potenciais e ainda como tais processos podem ser utilizados, por ele mesmo, a favor da terapia. Aquilo que por muitos pode ser visto como um defeito, tal como um sintoma, um comportamento inadequado, uma resistência, ou uma característica de personalidade, pode ser redefinido e utilizado para promover mudanças na relação do sujeito consigo, com o outro e seu sofrimento (ERICKSON, 1958). Este contexto, que comporta considerável diversidade de técnicas e formas de relação (ZEIG, 2001), é perpassado ainda por uma perspectiva do possível, na qual o problema trazido é compreendido dentro de narrativas que oferecem soluções possíveis para o mesmo (HALEY, 2001; WHITE, 2007). Assim, quando a pessoa se torna mais importante do que as regras e teorias, o terapeuta pode evitar a tentação de enquadrá-la em referenciais consagrados e apriori, ajudando-a a pensar e viver a situação de um modo mais flexível por meio de perspectivas que oferecem um encaminhamento concreto e acessível para o problema trazido. A negociação que se estabelece entre os protagonistas da relação permite que os passos sejam dados na sensação de que o processo avança e ganha, em seus distintos momentos, um caráter de novidade. 
No primeiro exemplo clínico descrito, pelo próprio relato posterior da cliente, é possível notar como a aceitação de trabalhar com a cliente naquela situação foi importante para seu processo terapêutico. Isso porque semelhante aceitação propiciou o oferecimento de um espaço onde os impasses vivenciados por D. Silvia pudessem ser trabalhados e sua história pudesse ser considerada de nova forma. Tratava-se de uma situação de ensino na qual a cliente era também aluna de psicologia inserida num grupo de estágio onde todos sabiam das restrições técnicas e éticas para que tal atendimento pudesse ali ocorrer ${ }^{2}$. Mas, apesar das várias restrições para isso (ou talvez por causa delas), a postura do pesquisador em atendê-la serviu como uma forma de consideração e confiança que a colocou numa disposição muito profunda para o trabalho terapêutico. Entre lágrimas disse aceitar as condições do processo e que daria o melhor de si para que o mesmo a beneficiasse e aliviasse suas dores, o que permitiu considerar um grande engajamento na proposta de terapia a ela oferecida.

Assim, no primeiro momento da terapia, o pesquisador se aproveitou dessa disposição e tomou uma atitude inesperada ao conferir à paciente a responsabilidade quanto a seu tratamento médico. Ao invés de repetir o movimento da família de pressioná-la insistindo com que se tratasse, ele apenas disse que confiaria em suas atitudes e não tocaria mais no assunto, pois cada um faria sua parte. Em seguida, ofereceu-lhe uma saída concreta e possível para um problema crucial de seu impasse - a elaboração de seu trabalho monográfico. Ela poderia se colocar na condição de repouso recomendada pelo médico e, ao mesmo tempo, trabalhar em seu projeto, pensando sobre ele, organizando suas idéias e gravando-as num pequeno gravador, tendo o trabalho apenas de revisar posteriormente a transcrição do material feita por outra pessoa. De certa maneira, o pesquisador, utilizando-se de uma intervenção que incluiu o paradoxo por ela vivido (ERICKSON; ROSSI, 1979), ofereceuIhe uma possibilidade de cuidar de si e realizar seu projeto de vida, idéias que até o momento eram incompatíveis para $D$. Silvia.

Já num momento posterior, as visões de seu pai durante o transe foram assumidas no sentido próprio que possuíam para cliente e não dissolvidas em alguma categoria psicológica consagrada como arquétipos ou processos imaginários (NEUBERN, no prelo). Assim, à medida que o pesquisador mostrava interesse pela figura de seu pai, como aparecia ali naqueles momentos, a cliente trabalhava de forma intensa na construção de uma nova forma de relação com o mesmo, saindo de uma profecia assustadora para a retomada de processos afetivos marcantes de sua própria história como filha. A aceitação de suas crenças, associada à possibilidade de resolução de sua pendência 
com o pai, consistiram em formas muito efetivas de oferecer à cliente a continuidade do engajamento no processo terapêutico, que culminou com importantes momentos de reconstrução histórica e reconfiguração de sua experiência de dor.

$\mathrm{O}$ caso de $\mathrm{D}$. Marlene também é bastante ilustrativo pela sua forma de buscar a terapia, como relatou a seu filho: "se é pesquisa, então, o negócio é sério." Para ela, era muito importante que sua história fosse escutada e recebesse atenção, pois além dos vários momentos de sofrimento, tratava-se de alguém que vivenciava uma posição dolorosa de isolamento social, que havia perdido sua profissão e o posto de ser referência para muitas pessoas. A desatenção de outros profissionais de saúde quanto a sua história era vivida como uma falta de seriedade, uma forma de menosprezo e desconsideração de sua própria pessoa, como ainda de ineficiência terapêutica. Daí porque, embora já tivesse realizado uma sessão de acolhimento inicial e outra de hipnose, o pesquisador compreendeu que seria importante não ceder à tentação de dar continuidade a um protocolo de pesquisa, já que as necessidades da cliente eram ligadas a uma situação de escuta e precisavam, naquele momento, ser atendidas sob a pena de que o contrato, em termos de engajamento emocional, não fosse efetivado. Foi curioso notar que, entre lágrimas, sorrisos e uma sucessão de eventos trágicos narrados, D. Marlene respirou profundamente e perguntou: "Então, Doutor, será que eu tenho jeito?"

Assim, ao finalmente ter acesso a um legítimo espaço de escuta, a cliente colocou-se mais disponível e receptiva para as ações do pesquisador que the ofereceu outras possibilidades para lidar com suas próprias demandas de conceber possibilidades e perspectivas que fugissem ao negativismo de seu pensamento. Ele optou por partir das expressões utilizadas por ela na terapia, isto é, de algo que já viesse dela, tanto como uma forma de usar suas referências, como de demonstrar que estava atento ao que havia dito. Para responder a esta última pergunta ("será que eu tenho jeito?"), o pesquisador se utilizou de outra expressão da cliente, reformulando-a em outros termos para apontar novas direções do processo terapêutico - "coisas dessa missa para lhe contar na próxima sessão". Então, procedeu a um conjunto de metáforas e histórias associadas à produção de certos fenômenos hipnóticos (ERICKSON; ROSSI, 1979) conotando que na trajetória histórica das pessoas existe tristeza e alegria, sofrimento e prazer e que isso não as impede de conquistar vitórias e aprender a enxergar suas vidas de outras maneiras. É interessante notar como após esta sessão D. Marlene apresentou melhoras significativas quanto a suas dores e sua 
depressão, passando ainda a buscar novas possibilidades de trabalho e convívio social.

No caso de D. Paula, o pesquisador se utilizou de sua autoridade e da confiança que a paciente depositava, pois, embora não enxergasse, naquele momento, uma possibilidade de futuro, estava disposta a colaborar com o tratamento oferecido pelo "doutor". Como a construção de sentidos e emoções em torno do choro era bastante contraditória, já que havia uma necessidade intensa de chorar e uma recriminação dessa necessidade, foi importante que o pesquisador pontuasse inicialmente que ele pediria algo difícil de ser realizado para $D$. Paula. $O$ que o pesquisador intencionava era exatamente retificar a dificuldade que a cliente sentia naquele momento em vista dessas contradições. Com isso, a prescrição do ritual de chorar frente ao altar de sua religião num lugar comum da casa envolvia, ao mesmo tempo, distintos elementos que buscavam proporcionar um contexto que favorecesse a produção de novos sentidos sobre 0 ato de chorar. Colocava-a exposta diante dos membros da família que se sentiam incomodados com seu choro, mas ao mesmo tempo diante de objetos sagrados do altar, o que poderia evocar nela e nos outros os sentimentos de respeito que as coisas sagradas evocam nos adeptos (ELIADE, 1965). Mas, o que talvez fosse ainda mais decisivo, é que, por meio de semelhante atividade, era a própria cliente quem escolheria o momento de chorar o que começava a Ihe incutir alguma possibilidade de vivenciar a tristeza de outra forma, como sujeito, e não de ser atropelada por ela (ERICKSON, 1958).

Tais ações do pesquisador, associadas a outras intervenções, proporcionaram a D. Paula a construção de mudanças significativas quanto a seu próprio sofrimento. De certa maneira, implicaram no reconhecimento de que havia um sofrimento intenso que quanto mais fosse negado, sob a idéia "os fortes não choram", mais seria difícil proporcionar-Ihe alguma mudança. Ao mesmo tempo, à medida que a própria cliente vivenciava essa experiência difícil de chorar, era ela mesma quem passava a reconhecer que havia ali um grande sofrimento e que o choro seria uma expressão natural do mesmo, ao invés de um ato de fraqueza. Desse modo, quando ela passou a decidir os momentos de chorar, abriu a possibilidade de sair de uma posição de paralisação, para um mover-se em sua própria trajetória de vida (MERLEAU-PONTY, 1949), podendo, finalmente, sair da subjugação de um sofrimento intenso para uma forma diferente de se relacionar com ele, onde se tornava possível manuseá-lo, provocá-lo, afastá-lo e até mesmo decidir quando ele poderia ocorrer. É assim que, além da concretização de mudanças importantes em termos sociais, como a busca de contatos, trabalho e familiares, a terapia proporcionou uma legítima forma de 
reconciliação consigo mesma (BINSWANGER, 1935), como parece ter indicado seu momento final de encontro para um bom café com a irmã já falecida.

\section{Considerações Finais}

Seria equivocado pressupor, de acordo com a discussão aqui levantada, que a proposta do contrato terapêutico não possa implicar em conflitos entre as necessidades dos clientes e dimensões teóricas e institucionais que perpassam a prática do terapeuta. Também seria errôneo considerar que tais dimensões devam ser descartadas situadas numa oposição irreconciliável com relação às demandas dos clientes, como se aquelas implicassem à princípio numa postura de distanciamento e de frieza quanto ao sofrimento de quem procura ajuda profissional de um terapeuta. O presente artigo refere-se ele mesmo a uma experiência que ocorreu no seio de uma instituição, com suas próprias necessidades (tais como de administração, formação e assistência) e dentro de uma proposta de pesquisa clínica com o objetivo de produzir conhecimento sobre a área. Seria, portanto, um contra-senso desprezar as próprias necessidades que o precederam que foram originárias tanto do contato clínico com os clientes, boa parte deles expressando sua insatisfação com determinadas posturas profissionais, como de problemas teóricos e institucionais. Daí porque o destaque conferido a conflitos como estes se deu exatamente para demonstrar alguns possíveis caminhos para superá-los, caminhos estes que não se prendem a uma abordagem específica, mas remetem à importância de uma consideração mais profunda do outro em sua condição humana. Dito de outro modo, essa consideração surge como um caminho imprescindível para que tais impasses sejam resolvidos e que, nos termos aqui discutidos, implica em duas vertentes principais.

Uma delas remete à necessidade de uma postura, da parte do terapeuta, de consideração com o outro o que permite a possibilidade da abertura de uma disposição para uma relação profunda, de acolhimento, partilha, importância e respeito com o cliente e aquilo que o mobiliza para a terapia, tal como já levantado por diversos autores (ANDERSON; GEHART, 2007; HYCNER, 1995). Entretanto, embora essa perspectiva não seja nova, é importante destacar, a partir das histórias clínicas aqui discutidas, que essa abertura ao outro remete necessariamente a uma relação de flexibilidade quanto ao marco teórico do terapeuta. A teoria precisa passar pelo questionamento do terapeuta que deve se colocar diante dela como sujeito. Isto porque, mesmo que o terapeuta possua uma disposição afetiva para considerar o outro, a relação com o cliente pode ficar comprometida caso desenvolva uma relação com a teoria de 
rigidez e servidão, onde a diversidade das expressões e vivências do outro sejam enquadradas, mesmo que de forma inconsistente, em conceitos que confirmam a teoria acima de qualquer contradição (GONZALEZ REY, 2003; MAHONEY, 1991; NEUBERN, 2001).

Esse tipo de atitude, permeada por operações de substancialização e reificação de conceitos (GONZALEZ REY, 2007), freqüentemente mina a consistência do contrato, pois, por mais que o cliente perceba boas intenções em seu terapeuta, viverá a sensação crescente de não ser compreendido e aceito por ele. Nas histórias clínicas aqui narradas houve a disposição do pesquisador em buscar captar o que era importante para as clientes, o que fazia sentido para elas e como, no cenário subjetivo delas, organizavam-se e articulavam-se os diferentes processos presentes em suas demandas. Desenvolveu-se um contexto que pode qualificar que as experiências de dor que traziam não estavam apriori dadas por um referencial teórico que determinava suas origens e relações com o mundo. Elas foram compreendidas na relação com as próprias clientes a partir das quais foi possível perceber como suas respectivas vivências se entrelaçavam a problemas cotidianos, como heranças e tramas familiares, a morte de um ente querido, a perda da condição de trabalho e a relação com outros profissionais. Vale destacar que semelhante atitude não consiste na proposta de supremacia de uma determinada abordagem, mas numa possibilidade concreta que é exercida por terapeutas de diferentes perspectivas teóricas que se posicionam como sujeitos diante de suas teorias, isto é, como seres criativos e capazes de questioná-las, propondo-lhes inovações que favoreçam um diálogo mais pertinente com as realidades vividas pelos clientes que o buscam (ERICKSON; ROSSI, 1979; NEUBERN, 2004).

Já a segunda dimensão, muito ligada à anterior, relaciona-se à proposta de um contexto pragmático e se refere a uma forma de considerar as possibilidades pragmáticas a partir da singularidade do cliente. Embora a questão do singular não seja nova na psicologia (BINSWANGER, 1958; MINKOWSKI, 1933), vale destacar que os obstáculos teóricos e técnicos aqui mencionados, com muita freqüência, impedem que ela se concretize no setting clínico, tantas vezes marcado pela busca de estabilidade e hegemonia, nas quais os terapeutas procuram adequar diferentes pessoas a uma mesma forma de trabalho ou aplicação técnica (ERICKSON, 1958; 1985; ROUSTANG, 2001). O que as histórias clínicas procuraram aqui demonstrar foi que, a partir dessa condição única de cada sujeito, foi possível propor um setting construído sob medida (ZEIG, 2001), isto é, adequado a suas formas de expressão e características, onde o cliente pudesse utilizar aquilo que é apenas seu a favor de sua própria terapia, seja na valorização de suas 
potencialidades, seja na busca de soluções para seu sofrimento. Em outras palavras, elas apontam para a importância de se compreender que existem diferentes vias para o processo de mudança e que, caso o terapeuta reconheça isso, maiores serão suas chances de atender à diversidade de pessoas e demandas que procurarem sua ajuda.

\section{Referências Bibliográficas}

ANDERSON, H. Conversation, Language and Possibilities. la ed. New York: Basic Books, 1997.

ANDERSON, H.; GOOLISHIAN, H. O Cliente é o Especialista. Nova Perspectiva Sistêmica, Rio de Janeiro, n. 3, p. 8-24, maio 1993.

ANDERSON, H.; GEHART, D. Collaborative therapy. Relationships and conversations that make a difference. $2 a$ ed. New York: Routledge, 2007.

BINSWANGER, L. De la psychothérapie. In :

l'analyse existentielle. Paris: Minuit, p. 119-147, 1935.

Introduction à

. The existential analysis school of thought. In: MAY, R.; ANGEL, E.; ELLENBERGER, H. (Orgs.). Existence. New York: Jason Aranson Book, p. 191-213, 1958.

ELI ADE, M. Le Sacré et le Profane. la ed. Paris: Gallimard, 1965.

ERICKSON, M. Naturalistic techniques of hypnosis. The American J ournal of Clinical Hypnosis, Phoenix, AZ, n. 1, p. 3-8, July 1958.

An introduction to the study and application of hypnosis in pain control. In: Rossi, E. (Org.). Healing in hypnosis. New York: Irvington, p. 217-278, 1985.

ERICKSON, M.; ROSSI, E. Hypnotherapy: An Exploratory Casebook. 1a ed. New York: Irvington, 1979.

FIGUEIREDO, L. C. Revistiando as Psicologias. Da Epistemologia à Ética das Práticas e Discursos Psicológicos. 3a ed. Petrópolis: Vozes, 1996.

GERGEN, K.; KAYE, J. Além da Narrativa na Negociação do Sentido Terapêutico. In: McNAMME, S.; GERGEN, K. (Orgs.). A Terapia Como Construção Social. Tradução por Cláudia Dornelles. Porto Alegre: Artes Médicas, cap 11, p. 201-222, 1998.

GONZALEZ REY, F. Sujeito e subjetividade. $1^{\underline{a}}$ ed. São Paulo: Thomson, 2003.

GONZALEZ REY, F. Psicoterapia, Subjetividade e Pós-Modernidade. 1 à ed. São Paulo: Thomsom, 2007.

HALEY, J. Aprendendo e ensinando a terapia. $1 \underline{\text { a }}$ ed. Tradução por Helena Mascarenhas. Porto Alegre: Artmed, 2001.

HYCNER, R. De pessoa a pessoa. Tradução por Elisa Gomes, Enila Chgas e Márcia Portella. São Paulo: Summus, 1995. 
$\mathrm{KOCH}$, S. Nature and Limits of Psychological Knowledge. American Psychologist, Washington, v. 36, n. 3, p. 257-269, march 1981.

LÉVY, A. Sciences Cliniques et Organizations Sociales. 1a ed. Paris: Puf, 1997.

MAHONEY, M. Human change process. 2a. ed. New York: Basic Books, 1991.

MERLEAU-PONTY, M. Phénoménologie de la perception. 1a. ed. Paris: Gallimard, 1949.

MINKOWSKI, E. Le Temps Vécu. la ed. Paris: Puf, 1933.

MORIN, E. La Méthode IV. Les Idées. 1a ed. Paris: Seuil, 1991.

NEUBERN, M. S. Complexidade e Psicologia Clínica: Desafios epistemológicos. 1a ed. Brasília: Plano, 2004.

A dimensão regulatória da psicologia clínica: o impacto da racionalidade dominante nas relações terapêuticas. Estudos de Psicologia, Natal, v. 10, n. 1, p. 73-81, janeiro a abril 2005a.

A Subjetividade Como Noção Fundamental do Novo Paradigma. In: GONZALEZ REY, F (Org.). Subjetividade, Complexidade e Pesquisa em Psicologia. 1 ed. São Paulo: Thomson, p. 53-79, 2005b. Hipnose e subjetividade: Utilizando a experiência religiosa em psicoterapia. Estudos de Psicologia, Campinas, no prelo.

ROUSTANG, F. L'I nfluence. la ed. Paris: Minuit, 1991.

VIEIRA FILHO, N.; NÓBREGA, S. Atenção psicossocial em saúde mental. Contribuição teórica para o trabalho terapêutico em rede social. Estudos de Psicologia, Natal, v. 9, n. 2, p. 373-379, maio a agosto 2004.

WHITE, M. Maps of narrative practice. 2a ed. New York: Norton \& Company, 2007.

WOLBERG, L. The Techniques of Psychotherapy. 2a ed. New York: Grune \& Stratton, 1967.

YAPKO, M. Treating depressions with hypnosis. 1a ed. Philadelphia: Brunner-Routledge, 2001.

ZEIG, J. Terapia Feita Sob Medida. 2a ed. Tradução por Adriana Machado e Eliete Pinto. Belo Horizonte: Diamante, 2001.

Endereço para correspondência

Maurício da Silva Neubern

Universidade de Brasília, Campus Universitário Darcy Ribeiro, ICC Sul, Instituto de Psicologia, Departamento de Psicologia Clínica (PCL), CEP 70910-900, Brasília-DF, Brasil

Endereço eletrônico: mneubern@hotmail.com

Recebido em: 24/11/2009

Aceito para publicação em: 15/03/2010 
Acompanhamento do processo editorial: Eleonôra Torres Prestrelo

\section{Notas}

* Doutor em Psicologia (UnB), Professor Adjunto do Departamento de Psicologia Clínica - PCL, Instituto de Psicologia - IP, Universidade de Brasília - UnB.

${ }^{1} \mathrm{O}$ presente artigo origina-se do projeto institucional "Subjetividade, hipnose e dor crônica: construindo o contexto terapêutico", desenvolvido pelo autor no Centro Universitário de Brasília (UniCeub). Contou com a aprovação do Comitê de Ética da instituição e inscrito no CONEP (Ministério da Saúde) de maneira que as regras quanto a estudo com seres humanos foram devidamente foram devidamente obedecidas. Recentemente este projeto foi aceito como projeto institucional na Universidade de Brasília, onde igualmente contou com a aprovação de seu comitê de Ética e inscrição no CONEP.

${ }^{2} \mathrm{~A}$ capacidade de acolhimento do grupo, os vínculos afetivos ali formados, a maturidade da cliente e algumas regras negociadas com o pesquisador foram decisivos para que tal atendimento pudesse ali ser realizado. Pretende-se discutir mais a fundo tais questões posteriormente em outro trabalho. 